\title{
Changes in referral rates following community psychiatric nurse attachment to a primary care team
}

\author{
ANDRew D. Wells, Senior Registrar in Psychiatry, The Douglas Inch Centre, \\ 2 Woodside Terrace, Glasgow, G3 7UY; JoHN M. EAGLES, Consultant Psychiatrist, \\ Royal Cornhill Hospital, Aberdeen; David HunTER, Systems Director, Aberdeen \\ Psychiatric Case Register; and Douglas G. Fowlie, Consultant Psychiatrist, \\ Royal Cornhill Hospital, Aberdeen AB9 2ZH
}

Over the past three decades there has been a shift in emphasis from hospital based to community care of psychiatric patients. Central to this change has been the development of the community psychiatric nursing services and an increase in its numbers. Until recently community psychiatric nurses (CPNs) were almost entirely hospital based, working as members of a multidisciplinary team and providing follow-up for psychiatric patients.

Increasingly, CPNs are now being attached to primary care teams where they have already shown their value in being more effective than routine treatment from a GP for neurotic patients, this leading to a small but non-significant fall in total resource usage and to patients expressing a preference for treatment in the primary care setting (Marks, 1985; Ginsberg et al, 1984).

The enthusiasm of CPNs towards working in the primary care setting, however, has not always been matched by that of their remaining hospital based colleagues who may feel that such a deployment of staff exacerbates the difficulties experienced by those caring for the patients with identified mental illness. CPNs are a finite resource, so time spent in primary care is time lost from the follow-up of hospital patients, with whom they have also proved their value; CPNs have been shown to be as effective as psychiatrists in out-patient follow-up of chronic neurotic patients, are cost-effective in this role and provide greater consumer satisfaction (Paykel $e t$ al, 1982; Mangen et al, 1983).

A major issue, then, is that by treating patients with psychiatric illness in primary care, do community psychiatric nurses prevent these patients from being referred or admitted to the remaining hospital based service?

\section{The study}

The present study examines a general practice in South Aberdeen where a CPN has been continuously attached since the beginning of 1984. It compares the referral rates from this practice during the two years prior to and the three years following this attachment, with those of other practices in the same catchment area.

The general practice at Rubislaw Place, Aberdeen, is typical of the larger city practices in South Aberdeen. At the time of the study, 1982 to 1986, it served a population of about 15,000 and had 7 GP partners, 2 GP trainees, 4 health visitors, 4 district nurses, 3 clinic nurses ( 1 full-time and 2 part-time), 1 part-time social worker and a practice manageress.

Since the beginning of 1984 a CPN has been continually attached to the practice, spending two sessions (eight hours) per week in this setting. The remainder of her time was spent in a hospital based multidisciplinary team. The CPN spent one session at the practice where she would take referrals and see patients. She tried to exercise flexibility with her remaining time and would respond to crisis calls from the practice as effectively as she could. No other practice in the South Aberdeen Catchment Area had a CPN attached during the study period.

The Grampian Psychiatric Case Register records all referrals to the psychiatric services in Aberdeen. Using the Case Register we examined the referral rates to the hospital based psychiatric services during the two years prior to and three years subsequent to the attachment of the CPN to the Rubislaw Practice and compared these with the referral rates from the rest of South Aberdeen. Referral rates were examined in terms of total referrals, first referrals, re-referrals and emergency referrals.

\section{Findings}

Table I shows the referral pattern of patients to psychiatric services, indicating the figures for all referrals, first referrals, re-referrals and emergency referrals respectively.

To investigate the effects upon numbers of referrals following the CPN's attachment, figures for the preattachment years (1982-1983) were combined in comparison with the summated figures for the postattachment years (1984-1986). The pre-attachment and post-attachment figures for referrals from Rubislaw Place and from all other South Aberdeen practices were then compared by means of $\chi^{2}$ tests. 
TABLE I.

Referral pattern before and after community nurse attachment

\begin{tabular}{|c|c|c|c|c|c|c|c|}
\hline & Year & 1982 & 1983 & 1984 & 1985 & 1986 & $\begin{array}{c}1982 / 83 v \\
1984-86\end{array}$ \\
\hline $\begin{array}{l}\text { All } \\
\text { referrals }\end{array}$ & $\begin{array}{l}\text { Total South } \\
\text { Aberdeen } \\
\text { Rubislaw Place } \\
\text { (\% of total) }\end{array}$ & $\begin{array}{r}1292 \\
141 \\
(10.9)\end{array}$ & $\begin{array}{r}1284 \\
141 \\
(11.0)\end{array}$ & $\begin{array}{r}1258 \\
120 \\
(9.5)\end{array}$ & $\begin{array}{r}1299 \\
112 \\
(8.6)\end{array}$ & $\begin{array}{r}1224 \\
106 \\
(8.7)\end{array}$ & $\begin{array}{l}\chi^{2}=6.79 \\
P<0.01\end{array}$ \\
\hline $\begin{array}{l}\text { First } \\
\text { referrals }\end{array}$ & $\begin{array}{l}\text { Total South } \\
\text { Aberdeen } \\
\text { Rubislaw Place } \\
\text { (\% of total) }\end{array}$ & $\begin{array}{r}668 \\
81 \\
(12.1)\end{array}$ & $\begin{array}{r}693 \\
82 \\
(11.8)\end{array}$ & $\begin{array}{r}594 \\
57 \\
(9.6)\end{array}$ & $\begin{array}{r}621 \\
49 \\
(7.9)\end{array}$ & $\begin{array}{r}624 \\
58 \\
(9.3)\end{array}$ & $\begin{array}{l}x^{2}=7.65 \\
P<0.01\end{array}$ \\
\hline $\begin{array}{l}\text { Re- } \\
\text { referrals }\end{array}$ & $\begin{array}{l}\text { Total South } \\
\text { Aberdeen } \\
\text { Rubislaw Place } \\
\text { (\% of total) }\end{array}$ & $\begin{array}{r}624 \\
60 \\
(9.6)\end{array}$ & $\begin{array}{r}591 \\
59 \\
(10.0)\end{array}$ & $\begin{array}{r}664 \\
63 \\
(9.5)\end{array}$ & $\begin{array}{r}678 \\
63 \\
(9.3)\end{array}$ & $\begin{array}{r}600 \\
48 \\
(8.0)\end{array}$ & $\begin{array}{l}\chi^{2}=0.52 \\
P-\text { N.S. }\end{array}$ \\
\hline $\begin{array}{l}\text { Emergency } \\
\text { referrals }\end{array}$ & $\begin{array}{l}\text { Total South } \\
\text { Aberdeen } \\
\text { Rubislaw Place } \\
\text { (\% of total) }\end{array}$ & $\begin{array}{r}285 \\
27 \\
(9.5)\end{array}$ & $\begin{array}{r}282 \\
41 \\
(14.5)\end{array}$ & $\begin{array}{r}263 \\
26 \\
(9.9)\end{array}$ & $\begin{array}{r}280 \\
15 \\
(5.4)\end{array}$ & $\begin{array}{r}248 \\
21 \\
(8.5)\end{array}$ & $\begin{array}{l}x^{2}=6.11 \\
P<0.02\end{array}$ \\
\hline
\end{tabular}

\section{Comment}

The results suggest that referrals to hospital services may be decreased by CPNs' involvement in primary care. The most significant effects appear to be those of decreasing the numbers of new referrals and of emergency referrals. This is an important finding as moves towards community psychiatry have sometimes stopped due to insufficient funding. Decreased referrals will result in a decrease in spending in the hospital setting and it may be economically feasible to attach more CPNs to primary care funded by these savings. This would result in a greater proportion of psychiatric patients being treated in the primary care setting, a move which would accord with patients' preferences (Marks, 1985).

A move of CPNs alone into the primary care setting could also carry some disadvantages. The decrease in emergency and first referrals in our study implies that the CPN may have been treating such patients. There is an obvious role for the psychiatrist in the assessment of many of these first contacts. Furthermore, the role of the CPN in the treatment of these patients would vary according to his/her training, skills and individual interests.

Retrospective studies suffer various drawbacks as there are often confounding variables which may obscure the causes of change. During this study two GPs left and were replaced - one in 1985 and one in 1986. New GP trainees arrived annually and there were other changes in staff (but not in staff numbers). It is possible that the new GPs were more psychiatric- ally and/or community orientated and that this influenced the practice to refer fewer patients. It could also be that the attachment of the CPN promoted a positive change in attitude towards community psychiatry in the practice thus leading indirectly to the fall in referrals. Prospective studies could further clarify the economic and other implications of deploying CPNs in primary care.

\section{Acknowledgements}

The authors are particularly grateful to community psychiatric nurse, Mary Melvin, whose work is the topic of this study. We are indebted to the staff of the Aberdeen Psychiatric Case Register. Our work is funded by a grant from Grampian Health Board.

\section{References}

Ginsberg, G., Marks, I. \& Waters, H. (1984) Cost benefit analysis of a control trial of nurse therapy for neuroses in primary care. Psychological Medicine, 14, 683-690.

Mangen, S. P., Paykel, E. S., Griffith, J. H., Burchell, A. H. \& MANCINI, P. (1983) Cost effectiveness of CPN or out-patient psychiatric care of neurotic patients. Psychological Medicine, 13, 407-416.

MARKs, I. (1985) Controlled trial of psychiatric nurse therapists in primary care. British Medical Journal, 290, 1181-1184.

Paykel, E. S., MANGen, S. P., Griffith, J. H. \& Burns, I. P. (1982) Community psychiatric nursing for neurotic patients: a controlled study. British Journal of Psychiatry. $140,573-581$. 